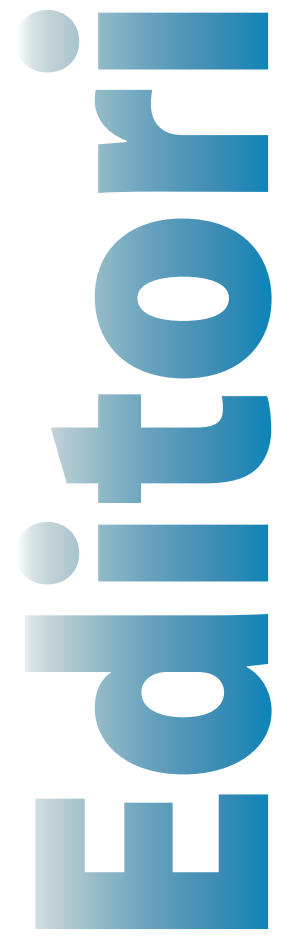

\title{
Plantes et aliments à xanthine, du régal à la santé
}

Qu'ont en commun le cacao, le café, le thé, si ce n'est d'être des plantes à xanthine, dont chacun connaît les propriétés cardiorespiratoires et psychoactives ? Il en est de même des feuilles de maté, ou de la noix de kola mastiquée plus que mangée et moins connue mais pourtant largement consommée dans une boisson célèbre. Toutes sont des plantes à la base des "breuvages " les plus largement consommés dans le monde, mêlés le plus souvent à du lait pour le cacao, même si l'infusion de maté est surtout consommée en Amérique du Sud. Ce
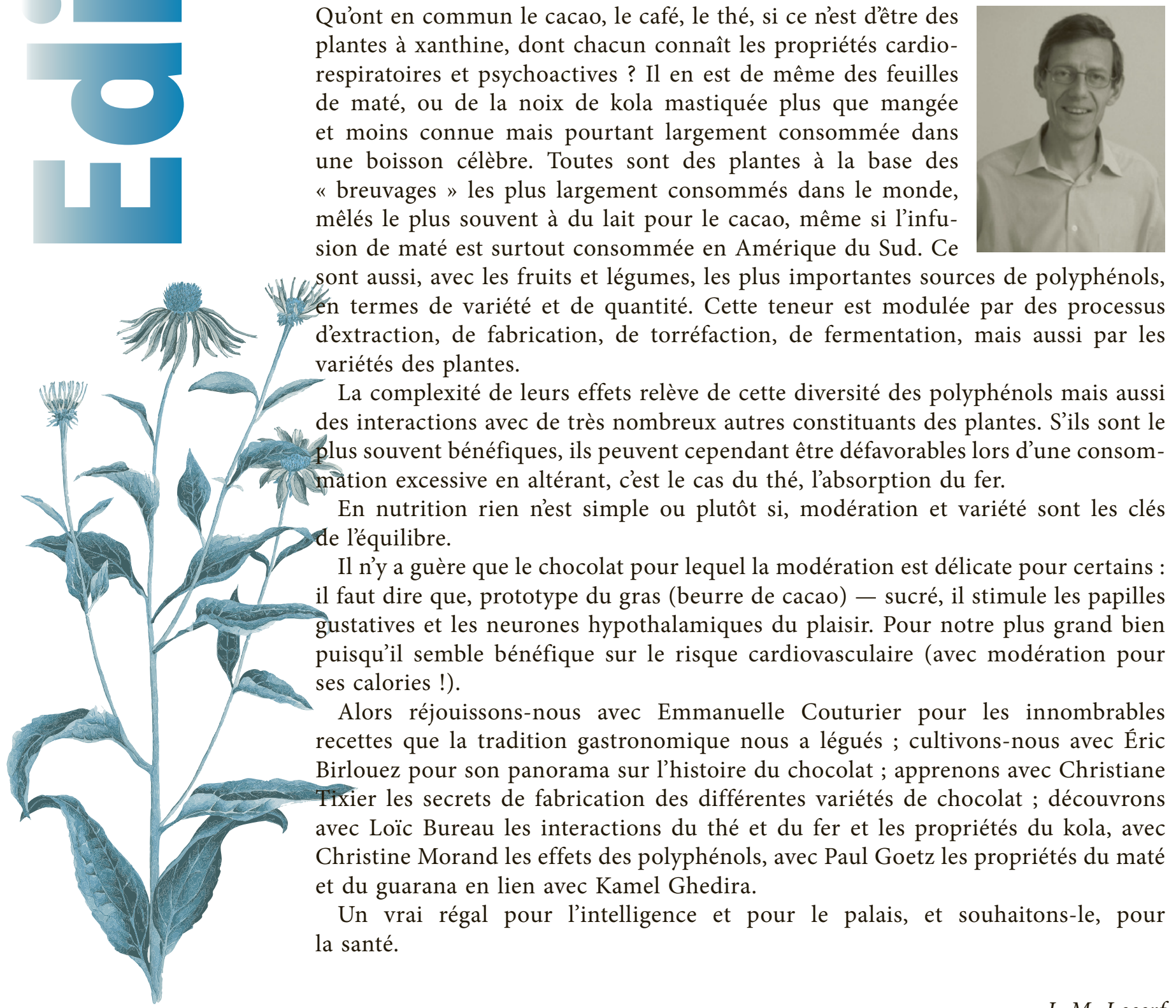
sont aussi, avec les fruits et légumes, les plus importantes sources de polyphénols, én termes de variété et de quantité. Cette teneur est modulée par des processus d'extraction, de fabrication, de torréfaction, de fermentation, mais aussi par les variétés des plantes.

La complexité de leurs effets relève de cette diversité des polyphénols mais aussi des interactions avec de très nombreux autres constituants des plantes. S'ils sont le plus souvent bénéfiques, ils peuvent cependant être défavorables lors d'une consommâtion excessive en altérant, c'est le cas du thé, l'absorption du fer.

En nutrition rien n'est simple ou plutôt si, modération et variété sont les clés de l'équilibre.

Il n'y a guère que le chocolat pour lequel la modération est délicate pour certains : il faut dire que, prototype du gras (beurre de cacao) - sucré, il stimule les papilles gustatives et les neurones hypothalamiques du plaisir. Pour notre plus grand bien puisqu'il semble bénéfique sur le risque cardiovasculaire (avec modération pour ses calories!).

Alors réjouissons-nous avec Emmanuelle Couturier pour les innombrables recettes que la tradition gastronomique nous a légués ; cultivons-nous avec Éric Birlouez pour son panorama sur l'histoire du chocolat ; apprenons avec Christiane Tixier les secrets de fabrication des différentes variétés de chocolat; découvrons avec Loïc Bureau les interactions du thé et du fer et les propriétés du kola, avec Christine Morand les effets des polyphénols, avec Paul Goetz les propriétés du maté et du guarana en lien avec Kamel Ghedira.

Un vrai régal pour l'intelligence et pour le palais, et souhaitons-le, pour la santé. 